\title{
DATA INTEROPERABILITY OF BUILDING INFORMATION MODELING AND GEOGRAPHIC INFORMATION SYSTEM IN CONSTRUCTION INDUSTRY
}

\author{
Wan Nor Fa'aizah Wan Abdul Basir ${ }^{1 *}$, Uznir Ujang ${ }^{1}$, Zulkepli Majid ${ }^{1}$, and Suhaibah Azri ${ }^{1}$ \\ ${ }^{1}$ Faculty of Built Environment and Surveying, Universiti Teknologi Malaysia, Johor, Malaysia- wannorfaaizah@gmail.com*, \\ \{mduznir, zulkeplimajid, suhaibah\}@utm.my
}

KEY WORDS: Building Information Modelling, Geographic Information System, Data Interoperability, Construction Industry

\begin{abstract}
:
Application of Building Information Modeling (BIM) in construction industry has been applied for many years back. This because BIM can provide a better advantage in construction industry in term of controlling and managing construction project during their life cycle. The advantages that can be provide by BIM is focusing on the indoor planning tasks. But, when the construction project involves, besides indoor planning, outdoor planning also is important part that need to be look up. To cover the outdoor planning in construction project, Geographic Information System (GIS) need to be applied. GIS can overcome this problem because GIS mainly for outdoor planning by using their spatial analysis. GIS can offer a high degree of geospatial information and can provide the detailed geometrical and semantic information of building to assisted across improve automation. Towards produce the improved preparation in construction project, BIM and GIS should be integrated. To integrate both domains, the data interoperability between them need to be investigate because they used different data standard. This study focusses on solving the data interoperability through the data integration between BIM and GIS to solve the problem of data mismatch and data missing during data translation process. Industry Foundation Classes (IFC) was used as a data standard to perform the data integration between BIM and GIS. The outcomes from this study show that when the data interoperability applied between BIM and GIS, the problem above can be solved, and the data dimension and their coordinate system also can be control.
\end{abstract}

\section{INTRODUCTION}

Modelling spatial objects in three-dimensional (3D) environment has now become common. With the existence of $3 \mathrm{D}$ data acquisition technology that can be used at the end-user level (i.e., LiDAR), 3D data has become accessible, and it simplifies the process of modeling 3D objects. Currently, the use of 3D spatial objects is used in various applications such as environmental modeling (Ledoux, 2008; Ujang et al., 2018), GIS-based Building Information Modeling (Atazadeh et al., 2017; Basir et al., 2018; Döllner and Hagedorn, 2007) and 3D city modeling (Biljecki et al., 2017; Jovanović et al., 2020; Salleh et al., 2021). Even so, there are still various issues as the $3 \mathrm{D}$ integration of objects between various fields sometimes require further assessments.

Building Information Model (BIM) is a platform which is used for data management which contains of spatial characteristics and building attributes (Eastman et al, 2011). From years of 2000s, BIM has been applied over the full cycle of construction project to assist the data of project cooperation and integration and to help the development activities.

Geographic Information System (GIS) is one of the methods that can be used to obtain and manipulate the spatial data concerning the topographic and current situation of the building site terrain. This effort may be found in many studies (Basir et al., 2018; Basir et al., 2020; Matarneh et al., 2019). Thus, information of the site and elevation can integrate with the building's location on the site. GIS was also utilized to resolve the difficulties of site layout planning (Sebt et al., 2008), for example to place the temporary facilities. To supervise the development procedure throughout the preconstruction phase, the integration of BIM and GIS may be used to recommend the significant benefits. This because BIM can offer geometry, spatial relationship, and capacities of building elements while
GIS can provide a spatial analysis for initial stage of the procurement procedure, and BIM be able to be used to show the outcomes of GIS analyses in 3D virtual world (Irizarry and Karan, 2012).

Even though GIS can be applied to manage the construction site terrain and pinpoint the transient things, a better stage of integration is required to exchange information between BIM and GIS data sets. During 2006, the Open Geospatial Consortium (OGC) set up a program for connecting the Architecture, Engineering and Construction (AEC) data model (e.g., CAD and BIM) with GIS work flows (Lapierre and Cote, 2007). The main issue in merging BIM and GIS data is the incompatibility among both knowledges, for example modelling and referencing system as the GIS data is constantly georeferenced and in two or two-and-a-half dimensions (i.e., one $\mathrm{z}$ value per 2D images) whereas the BIM entities have its own local coordinate systems and used the third dimension (Lapierre and Cote, 2007).

The differences between both domains either in term of data structure or data formats, it makes it is difficult to applied both applications. Because of these difficulties, buildingSMART has established and standardized the Industry Foundation Classes (IFC) data model within a substantial attempt to assist information interoperability in the construction industry. IFC is a unified model scheme that explains construction data. It utilizes an object-oriented approach to integrate data that is needed by the related stakeholders. But there are reasonable problems in resolving the integration problems such as some data loss or modify information and data exchange among heterogeneous system or industrial modelling software using IFCs was reported (Wu and Chang, 2016; El-Mekawy et al., 2012). Additionally, reported research has highlighted several problems related with the integration BIM and GIS (El-Mekawy et al., 2008). 


\section{DATA INTEROPERABILITY}

Several years ago, there are many applications that has been developed from both BIM and GIS to bring out the advantages of BIM and GIS technologies. Irizarry et al. (2013) develop an integrated GIS-BIM model that demonstrating the materials' movement, supplies' accessibility, and map of supply chain visually. The authors stated that the suggested method undergoes after the lack of semantic interoperability within GIS and BIM areas, and it needs that the client has understanding regarding these technologies and their functionalities. As example, the users require to understand just how BIM data is characterized in GIS model after importing data process happen. Microsoft Access database was applied to interpret the semantic data between BIM and GIS, but this method is quite ineffective, as well as it lacks the semantic interoperability. The similar case study has been looked out to prove the advantages that can be obtained after the semantic interoperability is being used.

After a few years of researchers studying the BIM and GIS standards, there are various data exchange formats that been created to assist the data interoperability. For example, to integrated BIM model with GIS domain (IFD 2014; IFG 2014), Industry Foundation Classes (IFC) for GIS (IFG) data model and buildingSMART Data Dictionary (IFD) were created. Although the purpose of IFG is to perform the data exchange over importing or exporting a specific data type, there are several heterogeneous classes for demonstrating building and geospatial data. Thus, using a various interoperable format for building and GIS classes is appropriate. The current method for represent the objects and their relationship that supplied by IFD Data Dictionary is by tagging all data from IFC format with Globally Unique ID (GUID).

Jetlund et al. (2020) enhance the interoperability between the $\mathrm{BIM}$ and GIS domains by connecting and synchronizing the main information theories from IFC and ISO/TC 211 standards. This main theories from the IFC and ISO/TC 211 have been connected in the UML model, along with transformations to application schemas for the Geography Markup Language (GML) and EXPRESS have been examined. Results indicate that IFC model might be explained as an ISO/TC 211 compatible with UML model and that conceptual theory from the ISO/TC 211 standards can be connected to the fundamental of IFC ideas.

Djuedja et al. (2019) investigated the issues of interoperability in BIM. The variety of participants involves, and the extremely long-life phase of the building reduce the capability to resolve the related issues. Once tracking the significance of interoperability of BIM, overviewing questions, and listing current resolutions is importance phase which highlight the requirement of interoperability in BIM. The result of this study is a review of faced interoperability challenges in BIM also aids to specify current solutions.

Zhu et al. (2019) intends an Open-Source Approach (OSA) that can recovered the geometric data in IFC out of spatial structure of IFC-Tree and translate the data into shapefile by using an Automatic Multipatch Generation process (AMG). A study on bridge model demonstrate OSA is extra effective than DIA and is equivalent to Feature Manipulation Engine (FME). This altered model is much simpler to operate and it can be applied in many purposes. By improving the data conversion from BIM to GIS, OSA can be connect BIM and GIS in a secure and useful approach. But their effectiveness would be more enhanced contrasted with FME.
Wang and Issa (2020) study on solving the data interoperability problems and focus the related study gaps by using the ontology to integrate BIM and GIS for indoor routing. In this research, extraction IFC data format from BIM was applied and it is commonly adopted by open standard in AECO industry. To create the integrated ontology, IfcOpenShell was used to obtain the indoor geospatial data from building information models. In order to query the integrated ontology model, SPARQL language query was used. By using the sample application from a sample IFC model that developed to examinate the recommended process, it's shows that the results from the ontology was acceptable for the integration BIM and GIS

De Gaetani et al. (2020) identify weaknesses in data exchange by evaluating various potential situations wherever a model IFC four-dimensions (4D) BIM model and associated Gantt charts were exchanged. Geometrical and nongeometrical data exchange over IFC files, the precise readability of 4D data, and existence of misplaced schedule data in Gantt charts after their import/export process happen were verified throughout the interoperability analysis of IFC data and Gantt charts. Results demonstrate that interoperability between the analysed programs is not constantly guaranteed, which offering practical understanding into convincing situations.

Hbeich and Roxin (2019) study on accomplish semantic interoperability between BIM (IFC) and GIS (CityGML), which improve the representation of building information into its features and its neighbouring atmosphere; also, they talk on modifying of PLU regulation into semantic enquiries. Throughout this study, they propose (1) BIM and GIS interoperability methods, and (2) linking the interoperable models, with PLU levels. The combination of the two methods helps they check the relationship and compliance of building elements with urban and construction rules. However, the approach is semi-automatic and rely on human intervention. This approach addresses (Problem 1) the building scale model of interoperability between IFC and CityGML, and (Problem 2) the connection between PLU rules and the multi-scale model.

Floros et al. (2020) provided an awareness about the information life cycle during Design \& Construction in the HS2 Rail Infrastructure development and examine the influence of present data organisation procedures and in specific Standards such as IFC, BIMGIS interoperability and life cycle of asset management. The products explain the stages of mis mapping throughout the exporting process to IFC which differs dependent on the infrastructure asset type. Analysis demonstrates that its deliverable by the establishment of extra semantic property sets to assist downstream of BIM-GIS interoperability for Operation and Maintenance (O\&M), allowing opportunity for potential job.

Ding et al (2020) proposed a new technique to create the feature vector and maps the IFC and CityGML schema over text mining methods at schema level by using linguistic-based semantic mapping which used the letter trigram-based word hashing method (WHSMM). By applying the WHSMM to acquire the semantic mapping precision and recall, the results were compared with a different linguistic-based method and its show that the performance of WHSMM is much more enhances to another method. Hence, to translate the IFC datasets into CityGML, the mapping applicants of WHSMM was applied. The translation findings shows that WHSMM's mapping applicant can be applied for functional data integration. By using this semantic mapping method, it can help to plan the IFC 
and CityGML schemas by decreasing the search area of the manual mapping method.

Biljecki and Tauscher (2019) discussed one of the initial stages to planning out a structure in faults and quality management in the perspective of BIM-GIS interoperability which refer to the empirical outcomes. Their aim is the translation from IFC to CityGML, recognizing various systematic errors possibly shared and/or special to the perspective of BIM-GIS conversion. It also examines the taxonomy and the possible affect when involved in application and displaying various weakness relating to IFC-sourced 3D city model. This study is also applicable with admiration to the increasing acceptance of translation among IFC and CityGML, theoretically assisting others to dodge numerous of the mistakes that can happen in the development and creating guidelines to establish a standard to estimate the presentation of the interoperability workflows.

Noardo et al. (2020) described the OGC CityGML and buildingSMART as a reference standard for georeferencing application in IFC and produce a steady translation between 3D city models and BIM. A test dataset in two reference standards were presented as a standard. The translation tools between CityGML and IFC, and georeferencing standards was explain and examined by using external volunteers. After the examination of the results, it was likely to announcement that there are tools and procedures offered to full explanation of the requirements, support georeferencing and data translation, clear guidelines to achieve such two tasks, as fine as solid technological explanations applying them, are still missing in functionalities. Those problems can be as practical set up point for developing the next GeoBIM integration plans.

Roxin and Hbeich (2019) provides a high-intensity explanation of the method for connecting the interoperability gap between GIS and BIM techniques. Following the review of guidelines offered in the studied application areas, the additional detail of interoperability problems applying and introduce current methods for achieving interoperability between models. Based on these methods, they also examine their method and the associated multi-scale modelling. This paper demonstrates in what way it permits attaining involvement between GIS and BIM practices, although maintaining reliable interpretation on the characteristics of the related techniques. They assume together with directory of potential effort need to be accomplished to achieve this concept.

\section{CASE STUDY}

This study describe the data interoperability during data exchange between BIM into GIS. Autodesk Revit was used to develop BIM model, FME used as a platform to perform translation process and ArcGIS used as GIS platform to show the results of translation and some analysis.

For the case study, BIM model that created applied for preconstruction planning but the data that provided can be used during the life-cycle of construction project. BIM model developed based on the requirement for the BIM Level of Detail (LOD) 400, which mean cover the building data structure that required for construction project including the costing data and project schedule. This BIM model not only cointained the geometrical data but also included the semantical data of the building. By using this BIM model, all information about the building for construction purpose will be illustrate.
Data interoperabilty was created before the data exchange can be done in FME platform. Figure 1 shows the flow of the process to perform the translation and where the data interoperability involve.

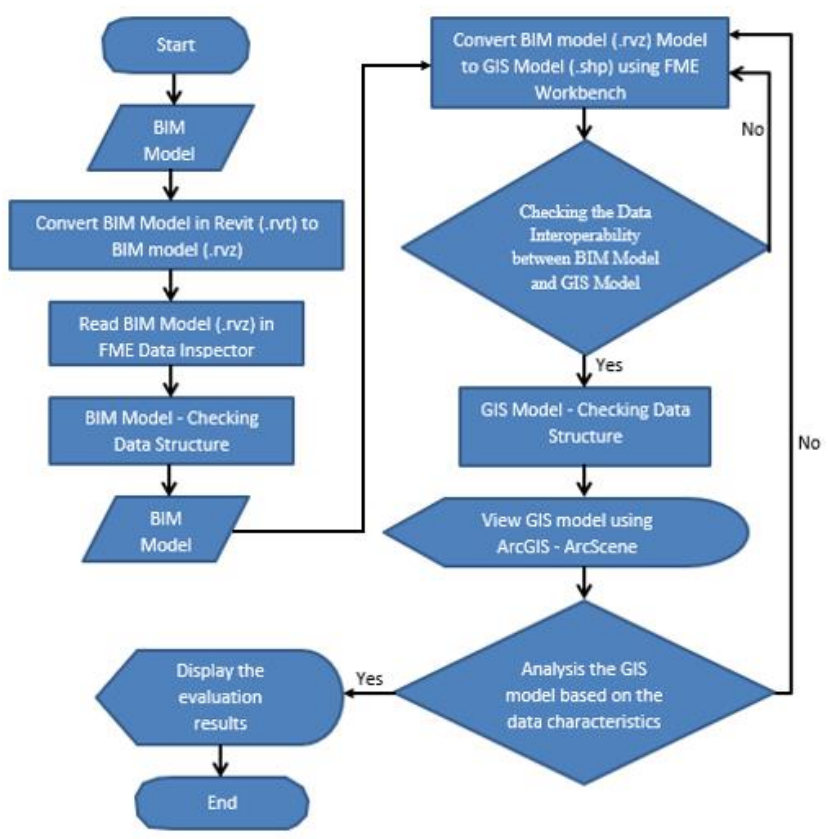

Figure 1. Flow of the translation process.

Figure 1 explain the flow of methodology for this research. To develop the BIM model, the as-built drawing has been used as a reference to design the 3D model of the building by using Autodesk Revit software. This model was built by researcher built on the real-world practices. During the development procedure, the data model of the BIM model was investigated to produce a data model that can be used for the GIS platform too.

For this study, Industry Foundation Classes (IFC) data model was used to explain the architectural, building and construction industry data. International Alliance for Interoperability (IAI) has developed IFC as an object-based file format with a data model to assist the interoperability in architecture, engineering, and construction (AEC) industry (buildingSMART International, 2019). For this study, IFC classes that involve are IfcWall, IfcWindow, IfcDoor, IfcCovering, IfcBeam, IfcColumn, IfcStorey, IfcRoof, IfcRailing, IfcRamp, IfcStair, IfcStairflight, and others. All this IFC classes was included in the data model that developed to build the data interoperability between BIM and GIS platform. This part of data model will not discuss in this paper.

After the BIM model developed in Autodesk Revit (geometric and semantic data), all data will translate to GIS platform by using FME platform. FME refer to the Feature Manipulation Engine that takes an ETL (extract, transform, load) attempt to data integration (safe.com, 2020). During the translation BIM into IFC, the data structure for each data geometric and semantic was checked to make sure all data was carried forward to IFC format without the problem of missing data and mismatch data because usually this is the major problem happen during the integration process (Basir 2018, Andrew, 2020). These problems occur because GIS and BIM used different data types and file formats. GIS doesn't support the BIM's primitive's data which produce difficulty which produce geometry data loss during exporting process. BIM does not 
establish semantic information and it turn into a crisis after semantic information losses throughout data export.

Next step after making sure that there is no problem which the missing data and mismatch data, the process of translation IFC into GIS can be carry out. This process also used FME as a medium to translate the data. Throughout this process, the missing and mismatch data problems also need to be check back in order bring all the geometric and semantic data into one platform which is ArcGIS. In ArcGIS platform, all data must be link between each other based on the data model development.

After the process is analysing the GIS data model based on the data characteristics which is focus on data dimension (scaling) and coordinate system data. Besides that, by using this GIS model, some query function also can be carried out for example of location of each element of the building including their semantic data.

\section{RESULTS AND ANALYSIS}

Autodesk Revit is one of the BIM software that has been used in supporting the architects, landscape designers, structural engineers, mechanical, electrical, and plumbing (MEP) engineers, and contractors for construction purpose. The software permits the clients to create a construction's building and its modules in $3 \mathrm{D}$, interpret the model with $2 \mathrm{D}$ design elements, and retrieve building data from the building model's database (Michael, 2012). Figure 2 show the results of BIM model in Autodesk Revit.

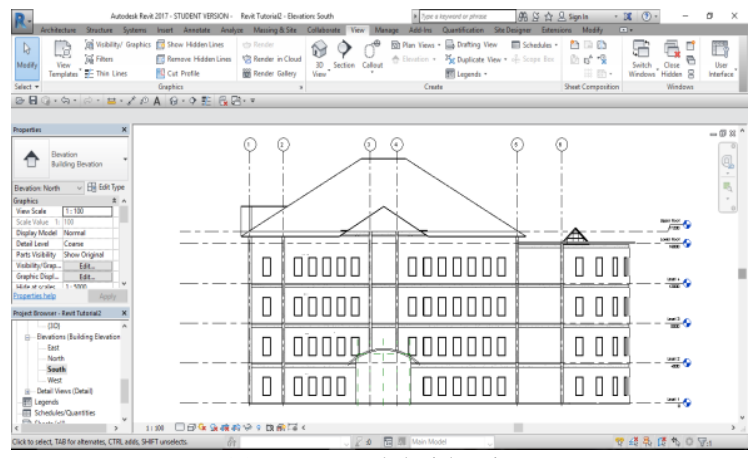

(a) BIM model side view

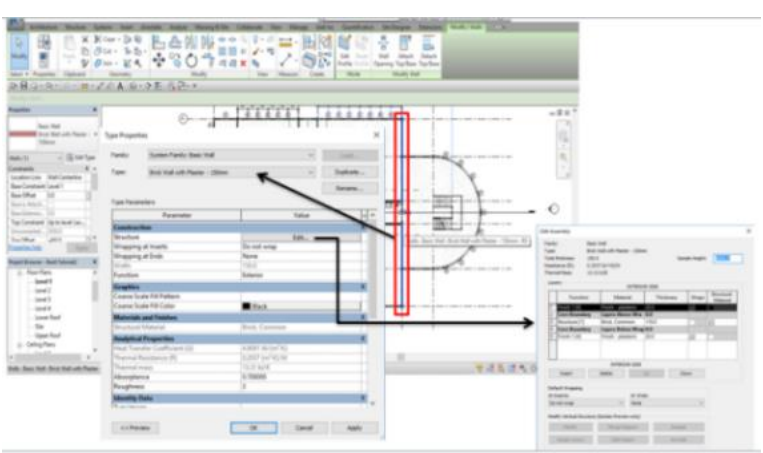

(b) Detail measurement of the wall element

Figure 2. BIM model in Aurodesk Revit.

Figure 3 show the 3D model in ArcScene ArcGIS after translation process. In this figure, it shows that all geometric data in BIM model was successfully carry forward into GIS platform after the translation process.

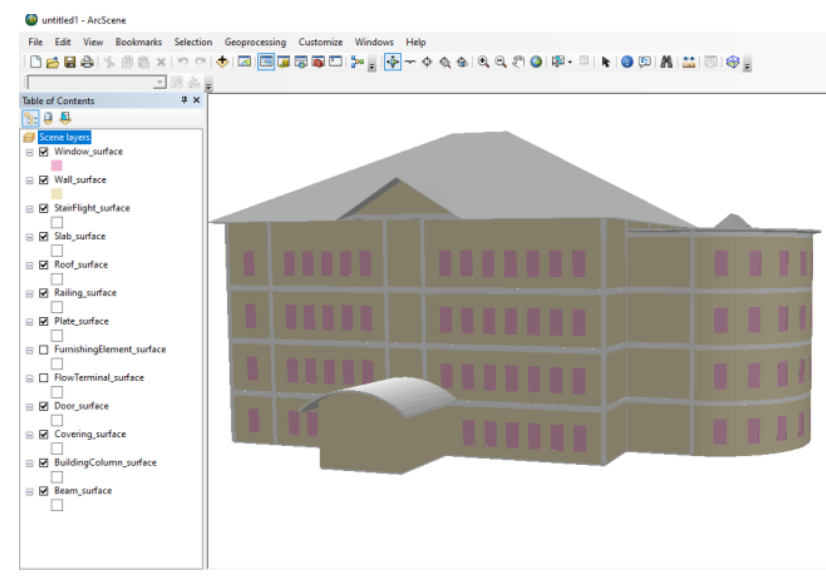

Figure 3. 3D model in ArcScene ArcGIS.

Figure 4 below show some query fuction that can be perform by using the 3D GIS model in ArcScene. This query function can be helpful to the life-cycle of constriction project because they can locate each entities/elements of the building using specific id or general information of the elements.

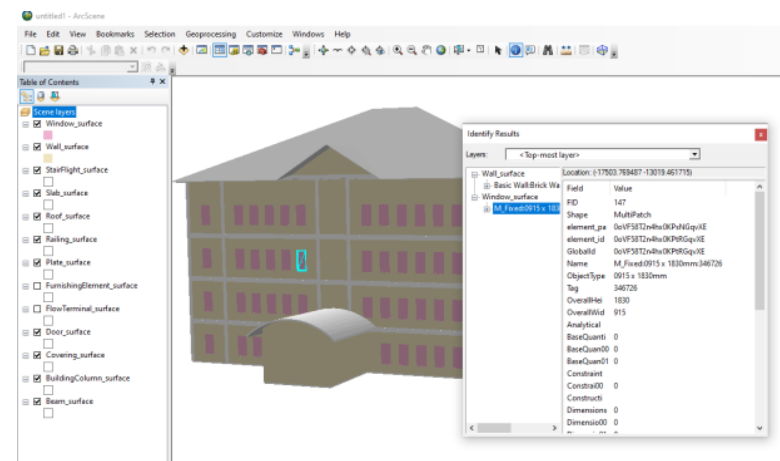

(a) Window querying

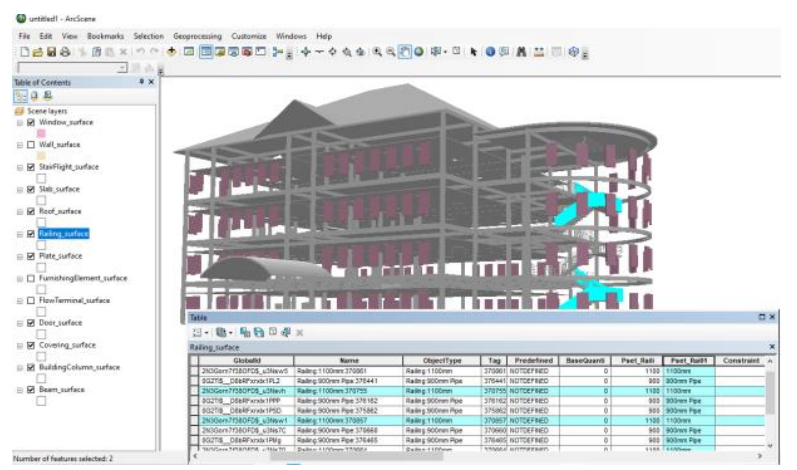

(b) Railing querying

Figure 4. The querying process of the window and railing elements in ArcScene.

After translation process, some analyses were carried out in order to check the data status. For example, in term of scaling and coordinate system. Figure 5 show the scaling analysis while Figure 6 show the coordinate system comparison. 


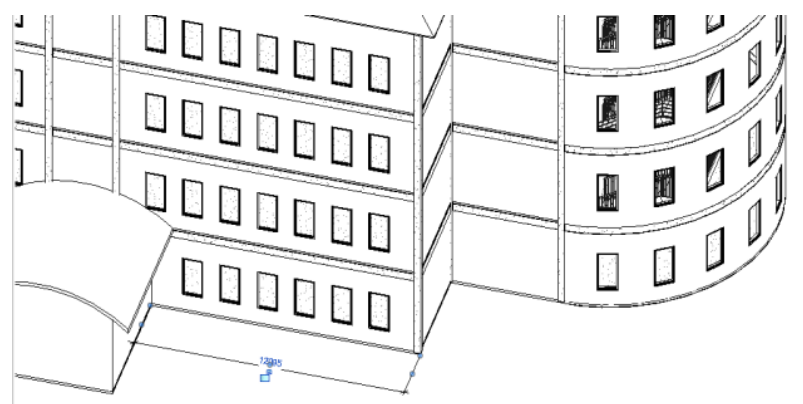

(a) Measurement in Revit - $12099 \mathrm{~mm}$

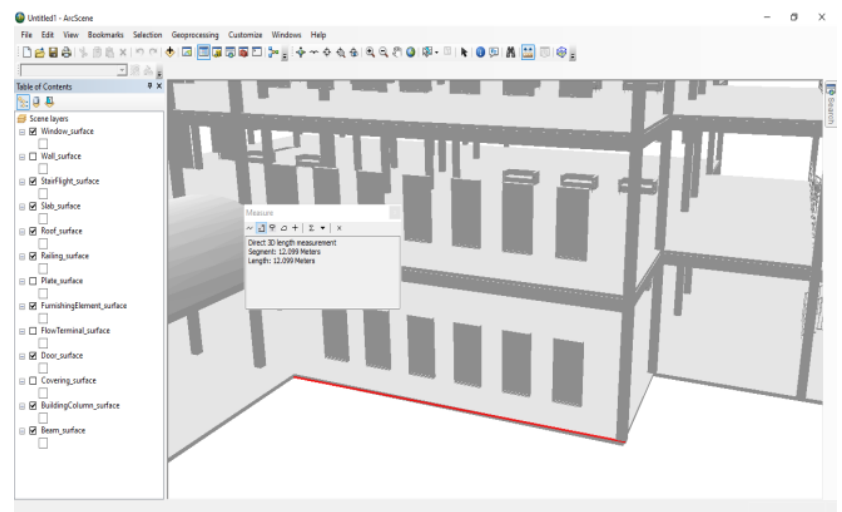

(b) Measurement in ArcScene - 12.099 m

Figure 5. Measurement comparison between Revit and ArcScene.

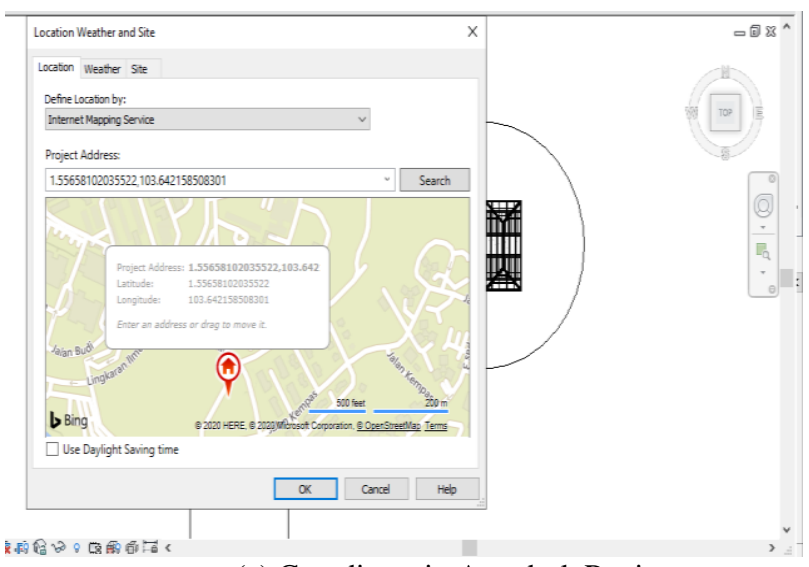

(a) Coordinate in Autodesk Revit

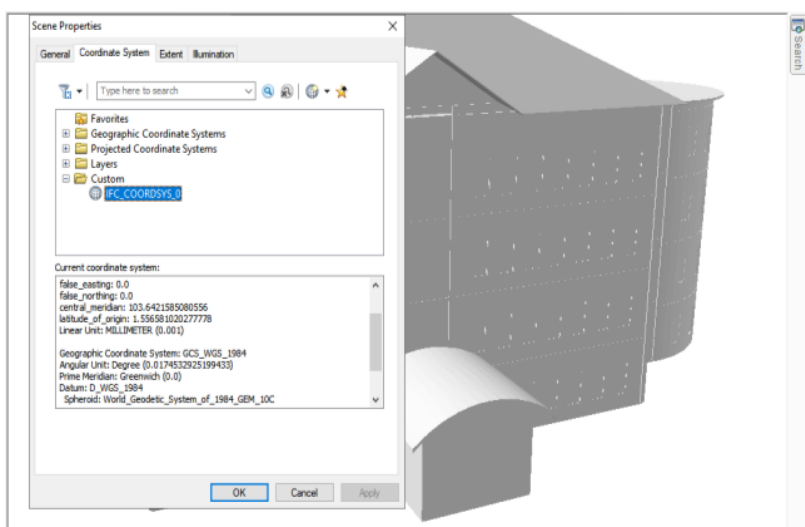

(b) Coordinate in ArcScene ArcGIS

Figure 6. Coordinate setting in both domains.
In the analysis steps, it shows that measurement and coordinate system between both domains is same which means all data was carry forward in corrected dimension.

\section{CONCLUSION}

This paper aims to describe the data interoperability in data translation between BIM and GIS without changing the data dimension in term of scaling and coordinate system. Results from this paper show the important of data interoperability throughout the process to bring all the data in the BIM model into GIS environment. In the future, this data will be extended by data matching functionality to represent the data linking between each data including BIM data and GIS data.

This study can be beneficial to construction industry because by using this study, preconstruction planning can be managed efficiently with the help of GIS. GIS can provide the spatial analysis function which can be used to planning purpose, managing the construction plan during the life cycle, and managing the data for the maintenance purpose. The example analysis that GIS can be used to helps the construction project is in term of site selection, site layout, route planning, and others. Future integration can be extended by having more advance spatial approach such as embedding topologial information in the model (Löwner, 2013; Salleh and Ujang, 2018; Ujang et al., 2019) and implementing complex data structures to the models (Azri et al., 2020; Keling et al., 2017; Kremer et al., 2013; Ujang et al., 2013).

\section{ACKNOWLEGEMENTS}

This research was partially funded by UTM Research University Grant, Vot Q.J130000.3652.02M78 and Vot Q.J130000.3652.02M57.

\section{REFERENCES}

Abanda, F.H., Vidalakis, C., Oti, A.H., Tah, J.H.M., 2015. A critical analysis of Building Information Modeling systems used in construction projects. Journal of Advances in Engineering Software, 90, 183-201.

Andrew, C., 2020. Common Patterns for BIM and GIS Integration. https://www.esri.com/arcgis-blog/products/arcgispro/transportation/common-patterns-for-bim-and-gisintegration/ (15 January 2020).

Atazadeh, B., Kalantari, M., Rajabifard, A., Ho, S., Champion, T., 2017. Extending a BIM-based data model to support 3D digital management of complex ownership spaces. International Journal of Geographical Information Science, 31, 499-522.

Azri, S., Ujang, U., Abdul Rahman, A., 2020. Voronoi classified and clustered data constellation: A new 3D data structure for geomarketing strategies. ISPRS Journal of Photogrammetry and Remote Sensing, 162, 1-16.

Basir, W.N.F.W.A., Majid, Z., Ujang, U., Chong, A., 2018. Integration of GIS and BIM Techniques in Construction Project Management - A Review. International Archives of the Photogrammetry, Remote Sensing and Spatial Information Sciences, XLII-4/W9, 307-316. 
Basir, W.N.F.W.A., Ujang, U., Majid, Z., Azri, S., Choon, T.L., 2020. The Integration of BIM And GIS in Construction Project - A Data Consistency Review. International Archives Photogrammetry Remote Sensing and Spatial Information Science, XLIV-4/W3-2020, 107-116.

Biljecki, F., Tauscher, H., 2019. Quality of BIM-GIS Conversion. ISPRS Annals of the Photogrammetry, Remote Sensing and Spatial Information Sciences, IV-4/W8, 35-42.

Biljecki, F., Ledoux, H., Stoter, J., 2017. Does a Finer Level of Detail of a 3D City Model Bring an Improvement for Estimating Shadows?, in: Abdul-Rahman, A. (Ed.), Advances in $3 D$ Geoinformation. Springer International Publishing, Cham, pp. 31-47.

buildingSmart International, 2019. Industry Foundation Classes $\begin{array}{lllll}\text { Version } & 4.2 & \text { bSI } & \text { Draft }\end{array}$ https://standards.buildingsmart.org/IFC/DEV/IFC4_2/FINAL/H TML/ (20 June 2021).

De Gaetani, C.I., Mert, M., Migliaccio, F., 2020 Interoperability Analyses of BIM Platforms for Construction Management. Journal of Applied Science, 10(13), 4437. https://doi.org/10.3390/app10134437.

Ding, L., Zhou, Y., Akinci, B., 2014. Building Information Modeling (BIM) application framework: The process of expanding from 3D to computable nD. Journal of Automation in Construction, 46, 82-93.

Ding, X., Yang, J., Liu, L., Huang, W., Wu, P., 2020. Integrating IFC and CityGML Model at Schema Level by Using Linguistic and Text Mining Techniques. IEEE Access, 8, 56429-56440.

Djuedja, J.F.T., Karray, M.H., Foguem, B.K., Magniont, C., Abanda, F.H., 2019. Interoperability Challenges in Building Information Modelling (BIM). In: Popplewell K., Thoben KD., Knothe T., Poler R. (eds) Enterprise Interoperability VIII. Proceedings of the I-ESA Conferences, vol 9. Springer, Cham. https://doi.org/10.1007/978-3-030-13693-2_23

Döllner, J., Hagedorn, B., 2007. Integration of GIS, CAD and $\mathrm{BIM}$ data with service-based virtual $3 \mathrm{D}$ city models. Integration von GIS-, CAD- und BIM-Daten mit Dienstbasierten Virtuellen 3D-stadtmodellen, 28-37.

Eastman, C., Teicholz, P., Sacks, R., Liston, K., 2011: BIM Handbook: A guide to Building Information Modeling for Owners, Managers, Designers, Engineers and Contractors. John Wiley \& Sons.

El-Mekawy, M., Ostman, A., Shahzad, K., 2008. Geospatial interoperability for IFC and CityGML: Challenges of existing building information database. Proceedings of Innovations '08, IEEE Conference, Dubai.

El-Mekawy, M., Ostman, A., Hijazi, I., 2012. An Evaluation of IFC-CityGML Unidirectional Conversation. International Journal of Advanced Computer Science and Applications, 3(5), 159-171.

Floros, G.S., Ruff, P., Ellul, C., 2020. Impact of Information Management During Design \& Construction on Downstream BIM-GIS Interoperability for Rail Infrastructure. ISPRS Annals of The Photogrammetry, Remote Sensing and Spatial Information Sciences, VI-4/W1, 61-68.

Hbeich, E., Roxin, A., 2019. Applying PLU Rules on Different BIM/GIS Interoperability Approaches. Informatica Economica, 23(3), 26-38.

Irizarry, J., Karan, E.P., 2012. Optimizing location of tower cranes on construction sites through GIS and BIM integration. Journal of Information Technology in Construction, 17, 351366.

Jetlund, K., Onstein, E., Huang, L., 2020. IFC Schemas in ISO/FC 211 Compliant UML for Improved Interoperability between BIM and GIS. ISPRS International Journal of GeoInformation, 9(4), 278 - 309.

Jovanović, D., Milovanov, S., Ruskovski, I., Govedarica, M., Sladić, D., Radulović, A., Pajić, V., 2020. Building Virtual 3D City Model for Smart Cities Applications: A Case Study on Campus Area of the University of Novi Sad. ISPRS International Journal of Geo-Information, 9(8), 476-500.

Keling, N., Mohamad Yusoff, I., Lateh, H., Ujang, U., 2017. Highly Efficient Computer Oriented Octree Data Structure and Neighbours Search in 3D GIS. in: Abdul-Rahman, A. (Ed.), Advances in $3 D$ Geoinformation. Springer International Publishing, Cham, pp. 285-303.

Kremer, M., Bommes, D., Kobbelt, L., 2013. OpenVolumeMesh - A Versatile Index-Based Data Structure for 3D Polytopal Complexes, in: Jiao, X., Weill, J.-C. (Eds.), Proceedings of the 21st International Meshing Roundtable. Springer Berlin Heidelberg, pp. 531-548.

Lapierre, A., Cote, P., 2007. Using Open Web Services for Urban Data Management: A testbed resulting from an OGC initiative for offering standard CAD/GIS/BIM services. Urban and Regional Data Management, CRC Press.

Ledoux, H., 2008. The Kinetic 3D Voronoi Diagram: A Tool for Simulating Environmental Processes, in: Oosterom, P., Zlatanova, S., Penninga, F., Fendel, E.M. (Eds.), Advances in $3 D$ Geoinformation Systems. Springer Berlin Heidelberg, pp. 361-380.

Löwner, M.-O., 2013. On Problems and Benefits of 3D Topology on Under-Specified Geometries in Geomorphology, Progress and New Trends in 3D Geoinformation Sciences. Springer Berlin Heidelberg, pp. 155-170.

Matarneh, S.T., Danso-Amoako, M., Al-Bizri, S., Gaterell, M., Matarneh, R., 2019. Building Information Modeling for facilities management: A literature review and future research directions. Journal of Building Engineering, 24, 100755.

Micheal, G., 2012. Architecture and The Lost Art of Drawing. The New York Times. https://www.nytimes.com/2012/09/02/opinion/sunday/architect ure-and-the-lost-art-of-drawing.html/ (2 February 2021).

Mutis, I., Paramashivam, A., 2019. Cybersecurity management framework for a cloud-based BIM model. Advances in Informatics and Computing in Civil and Construction Engineering, Springer Nature, 325-333. 
Noardo, F., Harrie, L., Ohori, K.A., Biljecki, F., Ellul, C., Krijnen, T., Eriksson, H., Guler, D., hints, D., Jadidi, M.A., Pla, M., Sanchhez, S., Soini, V.P., Stouffs, R., Tekavec, J., Stoter, J., 2020. Tools for BIM-GIS Integration (IFC Georeferencing and Conversions): Results from the GeoBIM Benchmark 2019. ISPRS International Journal of Geo-Information, 9, 502-537. https://doi.org/10.3390/ijgi9090502.

Roxin, A., Hbeich, E., 2019. Semantic Interoperability between BIM and GIS - Review of Existing Standards and Depiction of a Novel Approach. 36th CIB W78 - Information Technology for Construction, Sep 2019, Newcastle, United Kingdom. 〈hal02279633〉.

Safe.com, 2020. What is Data Integration. https://www.safe.com/what-is/data-integration/ (19 April 2020).

Salleh, S., Ujang, U., 2018. Topological information extraction from buildings in CityGML. IOP Conference Series: Earth and Environmental Science, 169, 012088.

Salleh, S., Ujang, U., Azri, S., 2021. Virtual 3D Campus for Universiti Teknologi Malaysia (UTM). ISPRS International Journal of Geo-Information, 10(6), 356.

Sebt, M.H., Karan, E.P., Delavor, M.R., 2008. Potential application of GIS to layout of construction temporary facilities. International Journal of Civil Engineering, 6(4), 235-245.
Ujang, U., Anton., F., Azri, S., Rahman, A.A., Mioc, D., 2013. Improving 3D Spatial Queries Search: Newfangled Technique of Space Filling Curves in 3D City Modeling. ISPRS Ann. Photogramm. Remote Sens. Spatial Inf. Sci., II-2/W1, 319-327.

Ujang, U., Azri, S., Zahir, M., Abdul Rahman, A., Choon, T.L., 2018. Urban Heat Island Micro-Mapping via 3D City Model. Archives Photogrammetry Remote Sensing and Spatial Information Science, XLII-4/W10, 201-207.

Ujang, U., Castro, F.A., Azri, S., 2019. Abstract Topological Data Structure for 3D Spatial Objects. ISPRS International Journal of Geo-Information, 8(3), 102-119.

Wang, N., Issa, R.R., 2020. Ontology-Based Integration of BIM and GIS for Indoor Routing. In: Construction Research Congress 2020: Computer Applications. American Society of Civil Engineers Reston, VA, 1010-1019.

Wu, B., Zhang, S., 2016. Integration of GIS and BIM for indoor geovisual analytics. International Archives for the Photogrammetry, Remote Sensing, and Spatial Information Sciences - ISPRS Archives, XLI-B2, 455-458.

Zhu, J., Wang, X., Wang, P., Wu, Z., Kim, M.J., 2019. Integration of BIM and GIS: Geometry from IFC to shapefile using open-source technology. Journal of Automation in Construction, 102, 105-119. 